\title{
The effect of passive smoking on the laryngospasm rate in children sedated during the esophagogastroduodenoscopy
}

\author{
Sibel Seckin Pehlıvan, $M D$, Ozlem Oz Gergın, MD, Adnan Bayram, MD, Derya Altay, MD, Duran Arslan, MD, Cihangir Biçer, MD, \\ Recep Aksu, MD.
}

\begin{abstract}
الأهداف : لمعرفة معدل تشنج الحنجرة مع التخدير أثناء إِجراء تنظير المريء المباء

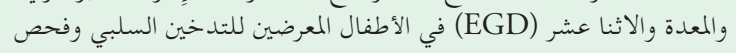

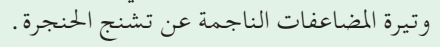

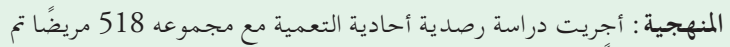

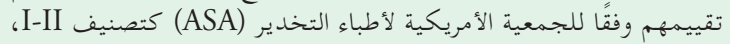

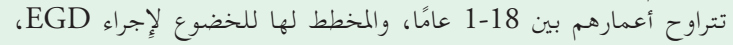

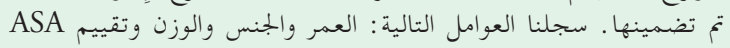

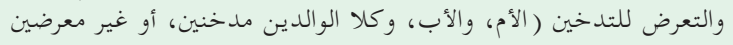

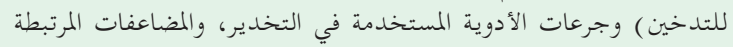

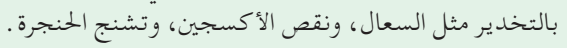

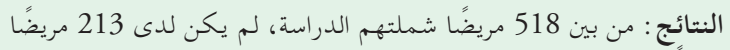

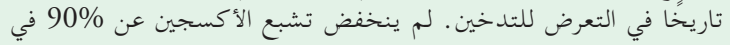

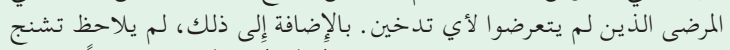

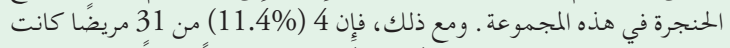

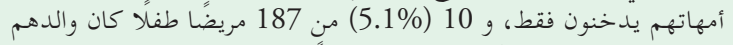

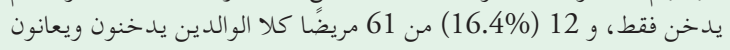
من تشنج الحنجرة ؤنثاء الإجراء.

الحخلاصة : زاد معدل تطور السعال وتشنج الحنجرة ونقص الأكسجين أثناء

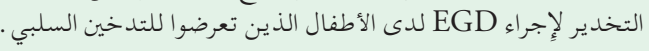

Objectives: To investigate the rate of laryngospasm with sedation during the esophagogastroduodenoscopy (EGD) procedure in children exposed to passive smoking and to examine the frequency of complications due to laryngospasm.

Methods: A single-blind, prospective, observational study with a total of 518 patients evaluated according to the American Society of Anesthesiologists (ASA) physical status as classification I-II, aged between 1-18 years, and planned to undergo an EGD procedure, were included. Age, gender, weight, ASA assessment, exposure to smoking (the mother, the father, both parents were smokers, or not exposed to smoking), drug doses used in sedation, and anesthesia-related complications, such as cough, decrease in oxygen saturation, and laryngospasm were recorded.
Results: Of the 518 patients included in the study, 213 had no smoking exposure history. Oxygen saturation did not decrease below $90 \%$ in patients who did not have any smoking exposure. In addition, no laryngospasm was observed in this group. However, 4 $(11.4 \%)$ of 31 patients whose mother only smoked, $10(5.1 \%)$ of 187 child patients whose father only smoked, and $12(16.4 \%)$ of 61 patients whose mother and father both smoked experienced laryngospasm during the procedure.

Conclusion: The rate of cough, laryngospasm, and hypoxia development increased during the sedation carried out in the EGD procedure in children who were exposed to passive smoke.

Clinicaltrial.gov ID: NCT03920046

Keywords: esophagogastroduodenoscopy, passive smoking, laryngospasm

Saudi Med J 2022; Vol. 43 (3): 275-282

doi: 10.15537/smj.2022.43.3.20210784

From the Department of Anaesthesiology and Reanimation (Pehlivan, Gergin, Bayram, Biçer, Aksu); and from the Department of Pediatric Gastroenterology (Altay, Arslan), Medical Faculty, Erciyes University, Kayseri, Turkey.

Received 1st October 2021. Accepted 26th December 2021.

Address correspondence and reprint request to: Dr. Sibel Seckin Pehlivan, Assistant Professor, Department of Anaesthesiology and Reanimation, Medical Faculty, Erciyes University, Kayseri, Turkey. E-mail: Sibelpehlivan@erciyes.edu.tr

ORCID ID: https://orcid.org/0000-0003-3215-5616

$\mathrm{E}$ sophagogastroduodenoscopy (EGD) is carried ${ }_{\text {out for diagnostic and therapeutic purposes in }}$ children. The procedure should be carried out with the safe, physical, and emotional comfort of the patient, anesthesiologist, and gastroenterologist. This principle is the primary purpose of sedation carried out in the endoscopy procedure. ${ }^{1}$ 
In pediatric patients, the EGD procedure can be carried out under deep sedation or general anesthesia. ${ }^{2}$ The deep sedation method is preferred over general anesthesia more due to the general anesthesias high cost, difficulty in administration and impracticality, the prolongation of the sleeping-awakening periods, and the higher rate of complications than the sedation procedure. ${ }^{3}$ Before sedation is administered to children, the presence of underlying diseases, airway anomalies, tonsil hypertrophy, and respiratory symptoms should be evaluated carefully, and sedation should be initiated by taking necessary precautions. ${ }^{4}$

Laryngospasm is a protective reflex occurring to protect the airway when the larynx is partially closed and breathing is impaired. It usually results in hypoxia, and if it continues, it may progress to pulmonary edema, arrhythmia, and cardiac arrest. ${ }^{5}$ The risk of developing laryngospasm increases during sedation in the presence of airway pathologies in children. The rate of laryngospasm development is 64/1000 in children with obstructive pulmonary disease and 96/1000 in children with acute upper respiratory disease. This risk decreases approximately 6 weeks after acute infection. ${ }^{6}$ During the induction of anesthesia and instrumental intervention of the airway, these patients are more prone to cough, laryngospasm, and hypoxia. ${ }^{7,8}$ Laryngospasm may develop due to anatomical and physiological reasons as well as respiratory problems caused by environmental factors. One of the most common environmental reasons is passive smoke exposure in children. ${ }^{5,9}$

Positive pressure ventilation, lidocaine, propofol, and muscle relaxants are recommended in treating laryngospasm. ${ }^{5,6}$ Although the causes, treatment, and results of laryngospasm in pediatric patients were frequently reported in the literature, studies on the rate of laryngospasm during EGD in children with exposure to passive smoke are rare.

We hypothesized that pediatric cases exposed to passive cigarette smoke that would increase airway problems in EGD procedures. This study primarily aimed to investigate the rate of laryngospasm with sedation during EGD procedures in children exposed to passive smoking and how it varies with age. Our secondary aim was to investigate the frequency of complications due to laryngospasm.

Disclosure. This study was funded by Erciyes University Scientific Research Projects Coordination Unit (ERU/BAP, Project No: TKB-2019-8801), Kayseri, Turkey.
Methods. This study was carried out with patients examined in the Pediatric Gastroenterology outpatient clinic, Erciyes University, Kayseri, Turkey, between 2019-2021 and who were given an appointment for an endoscopy procedure.

In this study, the rate of laryngospasm developing during sedation in EGD carried out in children with passive smoke exposure was investigated in a singleblind, prospective observational manner. The study protocol was approved by the Institutional Review Board of Erciyes University Faculty of Medicine Ethics Committee (2018/641). We obtained written informed consent from the parents and the older children. It was carried out according to the Declaration of Helsinki. The parents of 520 patients between the ages of 1-18 having the American Society of Anesthesiologists (ASA) physical status classification I-II, who were planned to undergo EGD for diagnostic or therapeutic purposes, were informed on the study, and their consents were obtained together with that of literate children. Patients with uncontrolled hypertension, severe heart and lung disease, allergy to the drugs used in the study, liver and kidney failure, pediatric smoking patients, and those with upper respiratory tract infection in the last 6 weeks were excluded from the study.

The first anesthesiologist obtained an anamnesis from the mother and father, questioned the parents' smoking habits, and kept the records. The endoscopist, and the second anesthesiologist who carried out sedation and evaluated the patient, were not informed about the study (blinded). Post-EGD data was collected by the nurses of the recovery rooms after being supervised by the second anesthesiologist. The demographic data of the patients (age, gender, weight), ASA assessment, exposure to smoking (the mother, the father, or both had smoked or not exposed to smoking), drug doses used in sedation, anesthesia-related complications, such as cough, a decrease in oxygen saturation, and laryngospasm, and the duration of sedation administered were recorded. Heart rate, respiratory rate, mean blood pressure, end-tidal carbon dioxide ${ }_{2}$ (Et-CO ; $_{2}$ Medtronic, CapnostreamTM35 Portable Respiratory Monitor, Israel), and bispectral index (BIS; Covidien, BIS Complete Monitoring System, USA) were monitored and recorded throughout the procedure. Blood pressure measurement was carried out at a 5-minute intervals during the endoscopy and was evaluated by averaging the mean blood pressure according to the age and weight of the children. According to their age, the oral intake of the patients was stopped 4-6 hours before the procedure. The patients were called to the endoscopy unit one hour before the procedure. Intravenous 
vascular access was established by an experienced nurse, and $1 / 3$ isodex solution was initiated at $10 \mathrm{~mL} / \mathrm{kg} / \mathrm{h}$. The patients were not premedicated before EGD. Approximately $10 \%$ lidocaine spray was applied to the posterior pharynx wall (to prevent gag reflex) in the sitting position. All patients were placed in the left lateral position, $3-4 \mathrm{~L} /$ minutes oxygen was administered through a nasal cannula, and Et- $\mathrm{CO}_{2}$ was monitored with a capnograph. For the induction of sedation, $0.05 \mathrm{mg} / \mathrm{kg}$ midazolam $(1 \mathrm{mg} / \mathrm{cc}$ midazolam diluted with $4 \mathrm{~mL} 0.9 \% \mathrm{NaCl}), 1 \mu / \mathrm{kg}$ fentanyl $(2 \mathrm{~mL}$ fentanyl diluted with $8 \mathrm{~mL} 0.9 \% \mathrm{NaCl}$ ), and $1.2 \mathrm{mg} / \mathrm{kg}$ propofol were administered. The drug was administered with a BIS value between 60-65 (BIS value of 0 is defined as deep anesthesia, 100 as wakefulness, and 60-65 as deep sedation). ${ }^{10}$ During the procedure, additional propofol $(0.5-1 \mathrm{mg} / \mathrm{kg})$ was added when the BIS score increased, and the patient started moving.

Laryngospasm is defined as the complete closure of the larynx, and it is a combination of symptoms. The presence of stridor, paradoxical thoracic/abdominal movements, peripheral oxygen saturation of $<90 \%$ (evaluated as hypoxia), mild (single cough), moderate (more than one episode of unsustained, $<5 \mathrm{sec}$ of coughing), and severe (sustained, $>5 \mathrm{sec}$ of coughing) cough reflex during EGD were considered as signs and findings indicating the development of laryngospasm. ${ }^{11}$ Lidocaine (1 $\mathrm{mg} / \mathrm{kg}$ dose) was administered prophylactically when symptoms appeared before the development of laryngospasm. In this case, if the sedation depth of the patients was appropriate according to BIS monitoring, additional propofol and midazolam were not added. ${ }^{12,13}$ When the endoscopy procedure was finished, the patient was evaluated according to the BIS value and aldrete recovery score. Patients were taken to the recovery room and were monitored for at least 2 hours. Those with an aldrete recovery score of 10 points or more were discharged. ${ }^{14}$ The relatives of the patients were told that the patient might have side effects (such as nausea, vomiting, abdominal pain, and respiratory distress), and in this case, they were advised to refer to the hospital. The development of cough, hypoxia, and laryngospasm during EGD, changes in Et-CO levels in capnography, and the effect of passive smoking on children according to age groups was evaluated by the status of smoking exposure (caused by mother, father, or both, or not exposed to smoking).

Statistical analysis. The data was evaluated using the Statistical Package for the Social Sciences, version 26 (IBM Corp., Armonk, NY, USA). Descriptive statistics were presented as the number of units (n), percentage $(\%)$, mean \pm standard deviation (SD), median (M), first quartile (Q1), and third quartile (Q3) values. The normal distribution of the data of numerical variables was evaluated by the Shapiro Wilk normality test and Q-Q graphs. For the midazolam variable with only one measurement and a normal distribution, comparisons between groups were carried out using the independent 2-sample t-test. Mann-Whitney $U$ test was used to compare the groups for numerical variables with other single measurements. In the inter-group and intra-group comparisons of heart rate, respiratory rate, blood pressure, and Et- $\mathrm{CO}_{2}$ variables before and after the procedure, a 2-way analysis of variance was used for repeated measurements from general linear models. Bonferroni correction was applied in multiple comparisons. Comparison of categorical variables according to exposure status was carried out with Pearson's Chi-square test. A $p$-value of $<0.05$ was considered significant.

In the study, the effects of age and cigarette exposure on cough, saturation, lidocaine rate, and incidence of laryngospasm during the procedure were investigated by single binary logistic regression analysis. Variables with a $p$-value of $<0.10$ in single binary logistic regression analyzes were included in the multiple binary logistic regression analysis. The Backward Wald method was used to determine the final variables that were effective on the dependent variable. Model fit was evaluated with the Hosmer Lemeshow test.

The number of patients in the study was calculated according to the incidence of laryngospasm in the sedation phase applied during EGD. In post power analysis, laryngospasm did not occur in 213 children who were not exposed to smoking $(0.0 \%)$, and $26(8.5 \%)$ of 279 children exposed to smoking developed laryngospasm. The power of the carried out test was found as $99 \%$ for alpha level 0.05 .

Results. Of the 520 patients included in the study, $213 \mathrm{had}$ no smoking exposure history. In their families, only the mothers of 35 children were smokers, fathers of 197 children were smokers, and both the parents of 73 children were smokers. Since it was found that 2 of the children included in the study later smoked, they were excluded from the study, and the data of 518 patients were statistically evaluated. There was no statistically significant difference between the groups in terms of demographic characteristics. However, exposure to smoking was significantly higher among female patients. The drug doses used during the procedure were adjusted according to the weight of the patients. No significant difference was found between the drug doses used between the 2 groups. The lidocaine 
dose used during sedation was higher in those exposed to smoking (Table 1).

There was no significant difference in heart rate and respiratory rates between the 2 groups before and after sedation. However, in the intra-group comparison, both the heart and respiratory rates were significantly lower after the procedure in both groups. Mean blood pressure was significantly higher before and after the procedure in the group exposed to smoking. In the comparisons within the group, the mean blood pressure values of both groups were lower after the procedure. There was no statistically significant difference in Et- $\mathrm{CO}_{2}$ values between the groups before and after the procedure, but there was a statistically significant increase in Et- $\mathrm{CO}_{2}$ values after the procedure in the intra-group comparisons in both groups. These differences were not clinically significant (Table 2).

The cough reflex that can trigger hypoxia during sedation administered in the EGD procedure was higher in patients with smoking exposure. Oxygen saturation did not decrease below $90 \%$ in patients who did not have any smoking exposure. In addition, no laryngospasm was observed in this group (Table 3). However, $4(11.4 \%)$ of 31 patients whose mother only smoked, $10(5.1 \%)$ of 187 child patients whose father only smoked, and $12(16.4 \%)$ of 61 patients whose mother and father both smoked experienced laryngospasm during the procedure (Table 4). Lidocaine administration rate was found to be the lowest in the group without exposure (Tables $3 \& 4$ ). It was observed

Table 1 - Demographic characteristics and anesthesia drugs.

\begin{tabular}{|c|c|c|c|}
\hline \multirow[t]{3}{*}{ Characteristics } & \multicolumn{2}{|c|}{ Exposure to smoking } & \multirow[t]{3}{*}{$P$-value } \\
\hline & No & Yes & \\
\hline & \multicolumn{2}{|c|}{ n (\%) } & \\
\hline \multicolumn{4}{|l|}{ Gender } \\
\hline $\begin{array}{l}\text { Male } \\
\text { Female }\end{array}$ & $\begin{array}{c}88(41.3) \\
125(58.7)\end{array}$ & $\begin{array}{l}93(30.5) \\
212(69.5)\end{array}$ & $0.001^{*}$ \\
\hline Age, years, M (range) & $10.0(5.0-14.0)$ & $11.0(6.0-15.0)$ & 0.083 \\
\hline Weight (kg), M (range) & $30.0(16.5-48.0)$ & $36.0(19.0-50.0)$ & 0.060 \\
\hline \multicolumn{4}{|l|}{ ASA status } \\
\hline $\begin{array}{l}\text { ASA-I } \\
\text { ASA-II }\end{array}$ & $\begin{array}{l}156(73.2) \\
57(26.8)\end{array}$ & $\begin{array}{c}238(78.0) \\
67(22.0)\end{array}$ & 0.208 \\
\hline $\begin{array}{l}\text { Propofol (mg), M ( } \mathrm{Q}_{1}- \\
\left.\mathrm{Q}_{3}\right)\end{array}$ & $50.0(30.0-80.0)$ & $50.0(30.0-80.0)$ & 0.926 \\
\hline $\begin{array}{l}\text { Midazolam (mg), M } \\
\left(\mathrm{Q}_{1}-\mathrm{Q}_{3}\right)\end{array}$ & $1.5(1-2)$ & $1.5(1-2.5)$ & 0.082 \\
\hline $\begin{array}{l}\text { Fentanyl ( } \mu \mathrm{gr}), \mathrm{M}\left(\mathrm{Q}_{1}-\right. \\
\left.\mathrm{Q}_{3}\right)\end{array}$ & $20.0(10.0-30.0)$ & $20.0(10.0-35.0)$ & 0.178 \\
\hline $\begin{array}{l}\text { Duration of endoscopy } \\
(\min ), M\left(Q_{1}-Q_{3}\right)\end{array}$ & $8.0(7.0-12.0)$ & $8.0(6.0-10.0)$ & 0.385 \\
\hline
\end{tabular}

ASA: American Society of Anesthesiology, M: median, $Q_{1}$ : first quartile, $\mathrm{Q}_{3}$ : third quartile, "significant difference $(p<0.05)$
Table 2 - Hemodynamic parameters.

\begin{tabular}{|c|c|c|c|}
\hline \multirow[t]{2}{*}{ Parameters } & \multicolumn{2}{|c|}{ Exposure to smoking } & \multirow[t]{2}{*}{$P$-value } \\
\hline & No & Yes & \\
\hline \multicolumn{4}{|c|}{ Mean \pm SD } \\
\hline \multicolumn{4}{|l|}{$H R$} \\
\hline Before EGD & $98.68 \pm 19.06$ & $98.10 \pm 16.97$ & 0.719 \\
\hline $\begin{array}{l}\text { After EGD } \\
\text { w-g TI }\end{array}$ & $\begin{array}{c}89.33 \pm 18.42 \\
p<0.001\end{array}$ & $\begin{array}{c}87.68 \pm 16.65 \\
p<0.001\end{array}$ & 0.288 \\
\hline \multicolumn{4}{|l|}{$R R$} \\
\hline Before EGD & $21.96 \pm 4.96$ & $21.78 \pm 4.64$ & 0.675 \\
\hline After EGD & $17.24 \pm 4.51$ & $17.54 \pm 4.28$ & 0.445 \\
\hline w-g TI & $p<0.001$ & $p<0.001$ & \\
\hline \multicolumn{4}{|l|}{$T A$} \\
\hline Before EGD & $75.09 \pm 13.85$ & $79.10 \pm 13.36$ & 0.001 \\
\hline After EGD & $69.45 \pm 10.93$ & $71.85 \pm 11.07$ & 0.015 \\
\hline w-g TI & $p<0.001$ & $p<0.001$ & \\
\hline \multicolumn{4}{|l|}{$\mathrm{Et}-\mathrm{CO}_{2}$} \\
\hline Before EGD & $28.06 \pm 5.65$ & $27.75 \pm 5.96$ & 0.548 \\
\hline After EGD & $29.77 \pm 4.39$ & $29.99 \pm 4.75$ & 0.598 \\
\hline w-g TI & $p<0.001$ & $p<0.001$ & \\
\hline \multicolumn{4}{|c|}{ Lidocaine need, $n$ (\%) } \\
\hline Yes & $15(7.0)$ & $84(27.5)$ & \multirow{2}{*}{$<0.001^{*}$} \\
\hline No & $198(93.0)$ & $221(72.5)$ & \\
\hline $\begin{array}{r}\text { EGD } \\
\text { rate, } \mathrm{T} \\
\text { w-g TI: int }\end{array}$ & $\begin{array}{l}\text { tandard deviat } \\
\text { nagogastroduoc } \\
\text { an arterial tensi } \\
\text { ip test statistics }\end{array}$ & $\begin{array}{l}\text { HR: heart rate, } \\
\text { copy, RR: resp } \\
\text { t- } \mathrm{CO}_{2}=\text { end tid } \\
\text { ificant differer }\end{array}$ & , \\
\hline
\end{tabular}

that the status of parents' smoking increased the risk of developing cough 3.2 fold, decrease in oxygen saturation by 6 fold, and the rate of lidocaine use during the procedure by 10 fold compared to children who had never been exposed to smoking (Table 5).

Discussion. This study revealed that the rate of cough, laryngospasm, and hypoxia occurring during EGD in pediatric patients increased with exposure to cigarette smoke.

Laryngospasm, one of the complications that develops due to airway pathologies, may develop in diseases affecting the respiratory tract and gastroesophageal reflux, especially in children up to the age of $5 .{ }^{15}$ In both cases, laryngospasm can occur with irritation of the pharynx and posterior wall of the pharynx. Smoking is also one of the most critical irritants that promote these situations. Cigarette smoke causes narrowing of small airways and increases occlusion volumes, with damage to the bronchial epithelium, increased permeability, and surfactant losses. ${ }^{16}$

Dennis et al. ${ }^{17}$ stated that the rate of development of cough, respiratory depression, and laryngospasm increased during anesthesia induction. This study determined more desaturation and bronchospasm in the group exposed to smoking, suggesting that the 
Table 3 - Comparison of patients' characteristics by smoking exposure.

\begin{tabular}{|c|c|c|c|c|}
\hline \multirow[t]{3}{*}{ Characteristics } & \multicolumn{2}{|c|}{ Exposure to smoking } & \multirow[t]{3}{*}{ Test statistics } & \multirow[t]{3}{*}{$P$-value } \\
\hline & No $(n=213)$ & Yes $(n=305)$ & & \\
\hline & \multicolumn{2}{|c|}{ n (\%) } & & \\
\hline \multicolumn{5}{|l|}{ Cough } \\
\hline $\begin{array}{l}\text { No } \\
\text { Yes }\end{array}$ & $\begin{array}{c}187(87.8) \\
26(12.2)\end{array}$ & $\begin{array}{c}211(69.2) \\
94(30.8)\end{array}$ & $\chi^{2}=24.411$ & $<0.001^{*}$ \\
\hline \multicolumn{5}{|l|}{ Laryngospasm } \\
\hline $\begin{array}{l}\text { No } \\
\text { Yes }\end{array}$ & $\begin{array}{c}213(100) \\
0(0.0)\end{array}$ & $\begin{array}{c}279(91.5) \\
26(8.5)\end{array}$ & $\chi^{2}=19.117$ & $<0.001^{*}$ \\
\hline \multicolumn{5}{|l|}{ Saturation } \\
\hline $\begin{array}{l}>90 \% \\
<90 \%\end{array}$ & $\begin{array}{c}210(98.6) \\
3(1.4)\end{array}$ & $\begin{array}{c}268(87.9) \\
37(12.1)\end{array}$ & $\chi^{2}=20.236$ & $<0.001^{*}$ \\
\hline \multicolumn{5}{|l|}{ Lidocaine need } \\
\hline $\begin{array}{l}\text { No } \\
\text { Yes }\end{array}$ & $\begin{array}{c}198(93.0) \\
15(7.0)\end{array}$ & $\begin{array}{c}221(72.5) \\
84(27.5)\end{array}$ & $\chi^{2}=34.089$ & $<0.001^{*}$ \\
\hline$\chi^{2}: c$ & i-squared tes & significant $\mathrm{d}$ & rence $(p<0.05)$ & \\
\hline
\end{tabular}

Table 4 - Comparisons by exposure to smoking groups.

\begin{tabular}{|c|c|c|c|c|c|}
\hline \multirow[t]{2}{*}{ Variables } & \multicolumn{4}{|c|}{ Exposure to smoking } & \multirow[t]{3}{*}{$P$-value } \\
\hline & $\begin{array}{c}\text { None } \\
(n=213)\end{array}$ & $\begin{array}{l}\text { Mother } \\
(\mathbf{n}=35)\end{array}$ & $\begin{array}{c}\text { Father } \\
(\mathrm{n}=197)\end{array}$ & $\begin{array}{c}\text { Both } \\
(\mathrm{n}=73)\end{array}$ & \\
\hline \multicolumn{5}{|c|}{$\mathbf{n}(\%)$} & \\
\hline \multicolumn{6}{|l|}{ Cough } \\
\hline $\begin{array}{l}\text { No } \\
\text { Yes }\end{array}$ & $\begin{array}{l}187(87.8) \\
26(12.2)^{\dagger}\end{array}$ & $\begin{array}{c}22(62.9) \\
13(37.1)^{ \pm . \$}\end{array}$ & $\begin{array}{l}149(75.6) \\
48(24.4)^{\ddagger}\end{array}$ & $\begin{array}{c}40(54.8) \\
33(45.2)^{\S}\end{array}$ & $<0.001^{*}$ \\
\hline \multicolumn{6}{|c|}{ Laryngospasm } \\
\hline $\begin{array}{l}\text { No } \\
\text { Yes }\end{array}$ & $\begin{array}{c}213(100.0) \\
0(0.0)^{\dagger}\end{array}$ & $\begin{array}{l}31(88.6) \\
4(11.4)^{ \pm . \S}\end{array}$ & $\begin{array}{r}187(94.9) \\
10(5.1)^{\ddagger}\end{array}$ & $\begin{array}{c}61(83.6) \\
12(16.4)^{\S}\end{array}$ & $<0.001^{*}$ \\
\hline \multicolumn{6}{|c|}{ Saturation } \\
\hline $\begin{array}{l}>90 \% \\
<90 \%\end{array}$ & $\begin{array}{c}210(98.6) \\
3(1.4)^{\dagger}\end{array}$ & $\begin{array}{l}29(82.9) \\
6(17.1)^{\ddagger . \$}\end{array}$ & $\begin{array}{c}183(92.9) \\
14(7.1)^{\ddagger}\end{array}$ & $\begin{array}{c}56(76.7) \\
17(23.3)^{\S}\end{array}$ & $<0.001^{*}$ \\
\hline \multicolumn{6}{|c|}{ Lidocaine need } \\
\hline $\begin{array}{l}\text { No } \\
\text { Yes } \\
\end{array}$ & $\begin{array}{c}198(93.0) \\
15(7.0)^{\dagger}\end{array}$ & $\begin{array}{c}25(71.4) \\
10(28.6)^{\ddagger . \S} \\
\end{array}$ & $\begin{array}{l}154(78.2) \\
43(21.8)^{\ddagger}\end{array}$ & $\begin{array}{c}42(57.5) \\
31(42.5)^{\S}\end{array}$ & $<0.001^{*}$ \\
\hline
\end{tabular}

mentioned pathological changes were responsible in passive smokers.

The younger the children, the longer the time spent with parents or other family members. If there is a smoking habit in the family, the risk of developing respiratory diseases becomes higher since the exposure duration to smoking increases. Therefore, smoking next to the child will adversely affect the respiratory system of a child who is in a growth and development period and breathes faster than an adult. ${ }^{18}$ Our study revealed that especially children between the ages of 1-11 were affected negatively. This situation may be related to spending more time with the mother and the high frequency of exposure.
Rodrigo et $\mathrm{al}^{8}$ stated that the incidence of cough, hypoxia, and laryngospasm was very high in young people during anesthesia induction. They also reported that, especially in children, the incidence of desaturation in the postoperative period was higher than in children who were not exposed to smoking.

A meta-analysis by Chiswell et $\mathrm{a}^{19}$ reported that smoking exposure in children increased anesthesia complications and was also one of the most critical risk factors for laryngospasm. The same researchers also stated that the studies on the interaction of children's cigarette exposure with anesthesia were insufficient. In this study, we thought that the high rate of cough, desaturation, and laryngospasm, especially in children aged 1-11 years, might be because they spend more time with their parents.

Aryanpur et $\mathrm{al}^{20}$ reported in their meta-analysis that systolic blood pressure increased in childhood and adolescence when exposed to passive smoking during the fetal period. Passive smoking exposure mainly begins in the intrauterine period in children. This exposure can be caused by the mother, father, or both. Therefore, no matter how early active smoking is initiated, it may not cause as much harm as passive exposure in childhood. Aryanpur et $\mathrm{al}^{20}$ determined passive smoking as a risk factor for developing hypertension in children. However, since long-term studies could not be carried out with these children, they could not fully explain the harm of hypertension in adulthood. In this study, similar to the results of Aryanpur et $\mathrm{al}^{20}$ it was observed that the average blood pressure values before and after the procedure were higher in those who were exposed to smoking compared to those who were not exposed to smoking. Nevertheless, in the blood pressure comparisons within the group, the blood pressure values of both groups decreased after the procedure. However, this decrease was within normal clinical limits. This effect was the result of sedation, and the drugs used had lowered blood pressure.

Moderate or deep sedation may be preferred in children during endoscopy. Although preservation of spontaneous breathing and airway reflexes seems advantageous with moderate sedation, deep sedation provides a safer environment. ${ }^{3,21}$ In this study, sedation with BIS was used. Thus, the propofol dosage was kept at a minimal level. Children with a history of active upper respiratory tract infection in the last 6 weeks were not included in the study, and it was aimed to minimize the complications that may develop due to infection.

There is no ideal anesthetic agent and protocol to be used alone in sedation during EGD. ${ }^{22}$ Therefore, drugs are used in combination. Propofol and ketamine 
Table 5 - Binary logistic regression analysis results.

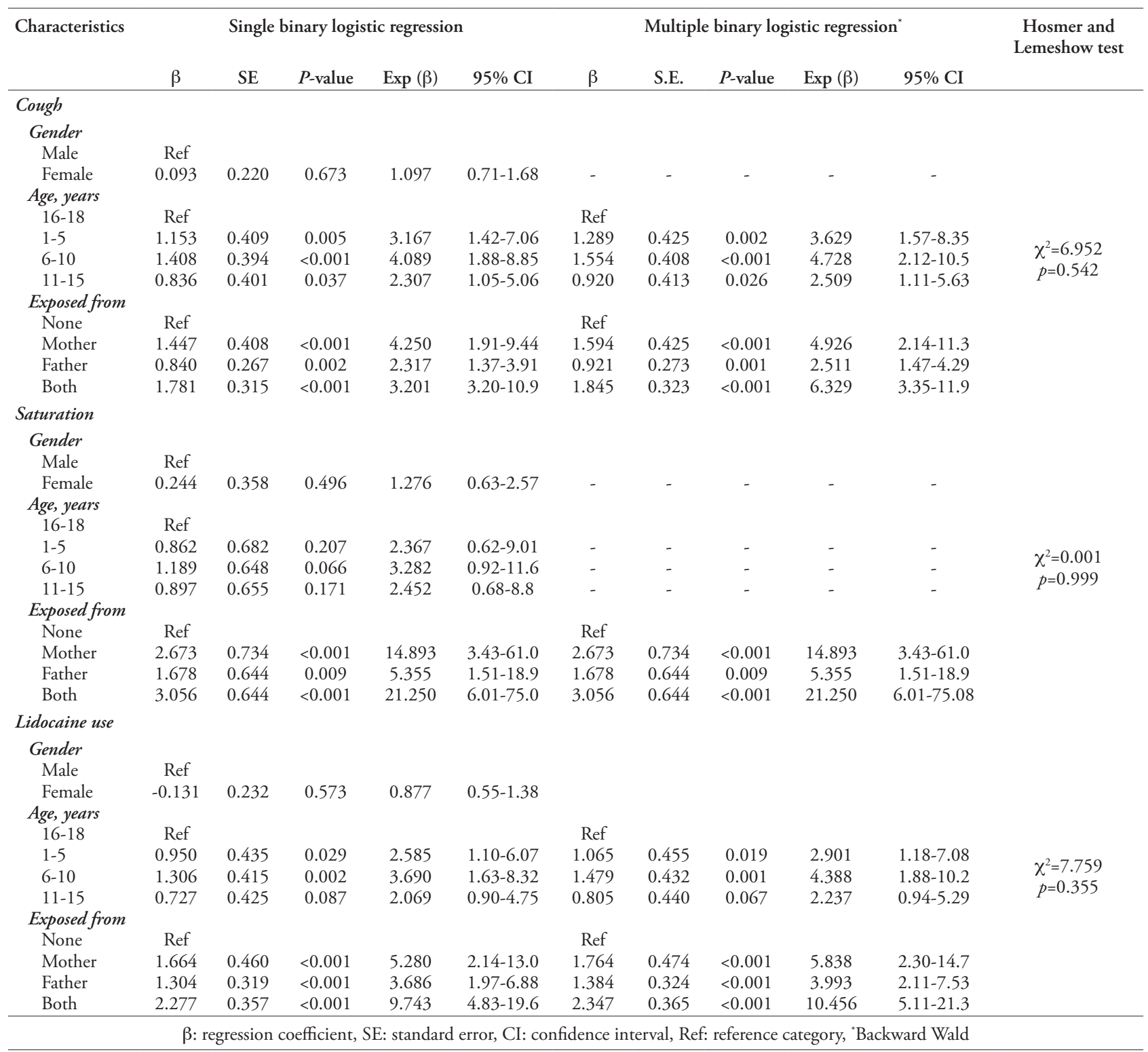

are the most commonly used hypnotics for sedation in children. Ketamine can be an effective agent during sedation in children, but it can lead to awareness during the procedure and to hallucinations and delirium after the procedure. Ketamine may increase airway secretions, postoperative nausea, and vomiting, and may cause cough and rarely, laryngospasm. ${ }^{23}$ Propofol shortens the induction time compared to the midazolam and fentanyl combination and facilitates intubation without disturbing the airway reflex. It is recommended for its effectiveness and safety in children. ${ }^{22,24}$ In this study, fentanyl, an opioid, was used to prevent pain caused by endoscopy and increase sedation depth. Midazolam was added to reduce propofol dose and anxiety and to provide antegrade amnesia. ${ }^{15}$ No drug-related complications or adverse effects were observed in the patients during or after the procedure.

Oxygen desaturation under sedation during endoscopy is an objective indicator of respiratory failure. Although oxygenation is sufficient during sedation, $\mathrm{CO}_{2}$ retention may develop. In recent years, microstream capnography has been developed, and patients' respiration is monitored with real-time graphics by measuring Et- $\mathrm{CO}_{2}$ waveforms in patients who are not 
intubated during sedation. While pulse oximetry shows $100 \%$ saturation, follow-up with a capnogram provides rapid and early diagnosis in cases where ventilation is insufficient. A study found that respiratory depression was detected 17.6 times faster with capnography follow-up than with standard monitoring. ${ }^{25}$ Using capnography during pediatric endoscopy has shown that the rate of children with ventilation abnormalities was higher than predicted. ${ }^{1,26}$ In this study, lidocaine was added to prevent hypoxia and laryngospasm that may develop in children by making early intervention according to the wave change in Et- $\mathrm{CO}_{2}$ without a significant decrease in oxygen saturation using a microstream capnograph.

Study limitations. In this study, patients' relatives provided incomplete or erroneous information while questioning their smoking habits. Although this was confirmed for older children, it was not possible to confirm this for younger children. Therefore, those who did not say that they smoked may have been overlooked because their parents' declaration could not be confirmed. The duration of exposure and dose response effect in children exposed to smoking could not be evaluated objectively. The total number of patients was low according to our study purpose, which was another limitation of our study.

This study evaluated heterogeneously that children were affected by exposure rather than the amount smoking of the parents. Pediatric patients could be evaluated in future studies by determining the number of cigarettes and daily exposure more homogeneously. Patient groups could be formed with equal distribution in study groups.

In conclusion, children who were exposed to passive smoke should be evaluated carefully in the pre-anesthesia period, taking the accompanying risk factors into account to avoid possible complications. Second, passive exposure might be a critical risk factor for developing hypertension. Third, the combination of propofol, fentanyl, and midazolam was once again shown to be a good combination during EGD. Fourth, with the capnography monitoring applied during EGD, complications due to hypoxia were detected in the early period, and precautions were obtained.

Acknowledgment. The authors gratefully acknowledge EnglishEdited.com (ee@englishedited.com) for English language editing.

\section{References}

1. Chung HK, Lightdale JR. Sedation and monitoring in the pediatric patient during gastrointestinal endoscopy. Gastrointest Endosc Clin N Am 2016; 26: 507-525.
2. Tringali A, Thomson M, Dumonceau JM, Tavares M, Tabbers MM, et al. Pediatric gastrointestinal endoscopy: European society of gastrointestinal endoscopy (ESGE) and European society for paediatric gastroenterology hepatology and nutrition (ESPGHAN) guideline executive summary. Endoscopy 2017; 49: 83-91.

3. Oh SH. Sedation in pediatric esophagogastroduodenoscopy. Clin Endosc 2018; 51: 120-128.

4. Thomson M, Tringali A, Dumonceau JM, Tavares M, Tabbers MM, Furlano R, et al. Paediatric gastrointestinal endoscopy: European society for paediatric gastroenterology hepatology and nutrition and European society of gastrointestinal endoscopy guidelines. J Pediatr Gastroenterol Nutr 2017; 64: 133-153.

5. Collins S, Schedler P, Veasey B, Kristofy A, McDowell M. Prevention and treatment of laryngospasm in the pediatric patient: a literature review. AANA J 2019; 87: 145-151.

6. Hampson-Evans D, Morgan P, Farrar M. Pediatric laryngospasm. Paediatr Anaesth 2008; 18: 303-307.

7. Lyons B, Frizelle H, Kirby F, Casey W. The effect of passive smoking on the incidence of airway complications in children undergoing general anaesthesia. Anaesthesia 1996; 51: 324-326.

8. Rodrigo C. The effects of cigarette smoking on anesthesia. Anesth Prog 2000; 47: 143-150.

9. Salih SK, Mukhtar BI. Effects of passive smoking on children health. Sudan JMS 2011; 6: 2.

10. Zhang H, Lu Y, Wang L, Lv J, Ma Y, Wang W, et al. Bispectral index monitoring of sedation depth during endoscopy: a metaanalysis with trial sequential analysis of randomized controlled trials. Minerva Anestesiol 2019; 85: 412-432.

11. Ki YM, Kim NS, Lim SH, Kong MH, Kim HZ. The effect of lidocaine spray before endotracheal intubation on the incidence of cough and hemodynamics during emergence in children. Korean J Anesthesiol 2007; 53: S1-S6.

12. Mihara T, Uchimoto K, Morita S, Goto T. The efficacy of lidocaine to prevent laryngospasm in children: a systematic review and meta-analysis. Anaesthesia 2014; 69: 1388-1396.

13. Tosun Z, Aksu R, Guler G, Esmaoglu A, Akin A, Aslan D, et al. Propofol-ketamine vs propofol-fentanyl for sedation during pediatric upper gastrointestinal endoscopy. Paediatr Anaesth 2007; 17: 983-988.

14. Aldrete JA. The post-anesthesia recovery score revisited. J Clin Anesth 1995; 7: 89-91.

15. Bartkowska-Śniatkowska A, Rosada-Kurasińska J, Ignyś I, Grześkowiak M, Zielińska M, Bienert A. Procedural sedation and analgesia in children undergoing digestive endoscopic procedures - paediatrician or anaesthesiologist? Prz Gastroenterol 2014; 9: 77-81.

16. O'Rourke JM, Kalish LA, McDaniel S, Lyons B. The effects of exposure to environmental tobacco smoke on pulmonary function in children undergoing anesthesia for minor surgery. Paediatr Anaesth 2006; 16: 560-567.

17. Dennis A, Curran J, Sherriff J, Kinnear W. Effects of passive and active smoking on induction of anaesthesia. BrJ Anaesth 1994; 73: 450-452.

18. Baker RJ, Hertz-Picciotto I, Dostál M, Keller JA, Nozicka J, Kotesovec F, et al. Coal home heating and environmental tobacco smoke in relation to lower respiratory illness in Czech children, from birth to 3 years of age. Environ Health Perspect 2006; 114: 1126-1132. 
19. Chiswell C, Akram Y. Impact of environmental tobacco smoke exposure on anaesthetic and surgical outcomes in children: a systematic review and meta-analysis. Arch Dis Child 2017; 102: 123-130.

20. Aryanpur M, Yousefifard M, Oraii A, Heydari G, KazempourDizaji M, Sharifi H, et al. Effect of passive exposure to cigarette smoke on blood pressure in children and adolescents: a metaanalysis of epidemiologic studies. BMC Pediatr 2019; 19: 161.

21. Friedt M, Welsch S. An update on pediatric endoscopy. Eur J Med Res 2013; 18: 24.

22. Van Beek EJ, Leroy PL. Safe and effective procedural sedation for gastrointestinal endoscopy in children. J Pediatr Gastroenterol Nutr 2012; 54: 171-185.
23. Green SM, Klooster M, Harris T, Lynch EL, Rothrock SG. Ketamine sedation for pediatric gastroenterology procedures. $J$ Pediatr Gastroenterol Nutr 2001; 32: 26-33.

24. Kim EH, Lee SK. Endoscopist-directed propofol: pros and cons. Clin Endosc 2014; 47: 129-134.

25. Sheahan CG, Mathews DM. Monitoring and delivery of sedation. Br J Anaesth 2014; 113: ii37-ii47.

26. Vargo JJ, Zuccaro G Jr, Dumot JA, Conwell DL, Morrow JB, Shay SS. Automated graphic assessment of respiratory activity is superior to pulse oximetry and visual assessment for the detection of early respiratory depression during therapeutic upper endoscopy. Gastrointest Endosc 2002; 55: 826-831. 